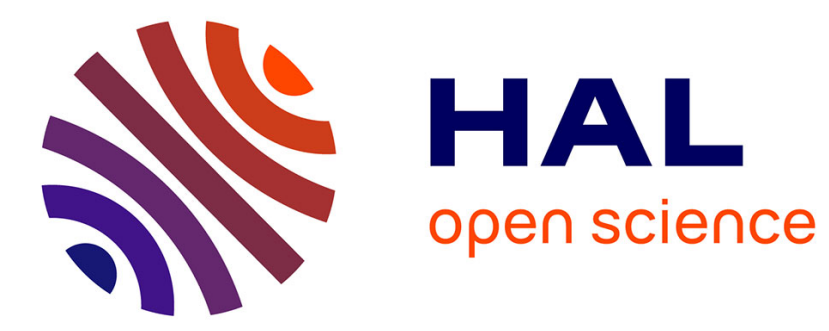

\title{
Optimal sizing and allocation of distributed generation for reliable energy distribution accounting for uncertainty
}

\author{
Rodrigo Mena, Yan-Fu Li, Martin Hennebel, Carlos Ruiz, Enrico Zio
}

\section{- To cite this version:}

Rodrigo Mena, Yan-Fu Li, Martin Hennebel, Carlos Ruiz, Enrico Zio. Optimal sizing and allocation of distributed generation for reliable energy distribution accounting for uncertainty. ESREL 2013, Sep 2013, Amsterdam, Netherlands. pp.1-8. hal-00839908

\section{HAL Id: hal-00839908 \\ https://hal-centralesupelec.archives-ouvertes.fr/hal-00839908}

Submitted on 1 Jul 2013

HAL is a multi-disciplinary open access archive for the deposit and dissemination of scientific research documents, whether they are published or not. The documents may come from teaching and research institutions in France or abroad, or from public or private research centers.
L'archive ouverte pluridisciplinaire HAL, est destinée au dépôt et à la diffusion de documents scientifiques de niveau recherche, publiés ou non, émanant des établissements d'enseignement et de recherche français ou étrangers, des laboratoires publics ou privés. 


\title{
Optimal sizing and allocation of distributed generation for reliable energy distribution accounting for uncertainty
}

\author{
R. Mena, Y. Li, E. Zio \\ France, at École Centrale Paris - Supelec, France \\ M. Hennebel \\ Supelec, France \\ C. Ruiz \\ Universidad Carlos III de Madrid, Spain \\ E. Zio \\ Energy Department, Politecnico di Milano, Italy
}

Chair on Systems Science and the Energetic Challenge, European Foundation for New Energy - Electricité de

ABSTRACT: This paper presents a computational framework for the integration of renewable generators DG into an electrical power distribution network. Reliability of power supply is targeted, taking into account the uncertainty of loads and renewable energy sources and, in addition to the failure behavior of the system components. The computational framework developed integrates Monte Carlo simulation for the generation of the uncertain scenarios of operation and Optimal Power Flow (MCS-OPF) into a multi-objective NSGA-II search engine. NSGA-II searches for Pareto optimal (non-dominated) solutions of allocation of DG in the electrical power network. Optimality is sought with respect to power service reliability and cost performance indicators, and is evaluated by MCS-OPF, for each allocation proposed by NSGA-II. A case study is presented to discuss the implications of the new framework and propose further challenges.

\section{INTRODUCTION}

We consider the optimization problem of distributed generation (DG) sizing and allocation. This is a relevant problem in modern power grid design and extension planning. The objective functions typically considered are based on three types of indicators: cost-based (Atwa et al., 2010, Falaghi et al., 2011, Liu et al., 2011, Martins \& Borges, 2011, Raoofat, 2011, Viral \& Khatod, 2012), operational (reliability) (Borges, 2012, Ganguly et al., 2010, Martins \& Borges, 2011) and technical (Atwa et al., 2010, Hejazi et al., 2010). Power flow (PF) equations used to evaluate the objective functions. Evolutionary algorithms (EAs) have been proposed as an effective way of handling the complexity of the optimization problem related to DG sizing and allocation (Alarcon-Rodriguez et al., 2010). Among the EAs commonly used are particle swarm optimization (PSO) (Ganguly et al., 2010), differential evolution (DEA) (Hejazi et al., 2010) and genetic algorithms (GA) (Falaghi et al., 2011, Liu et al., 2011, Martins \& Borges, 2011, Raoofat, 2011).

A relevant role in the optimality of the solutions is played by the uncertainties in the system, due to the inherent uncertain behavior of the renewable primary energy sources, unexpected failures or stoppages of the generation units, to variability in the main power supply, interruptions of the power flow in the feeders, failures in the components, fluctuations in the loads and energy price, etc.

We address the problem by a computational framework, in which the main sources of uncertainties are incorporated by a Monte Carlo simulation and Optimal Power Flow (MCS-OPF) model within a multi-objective optimization (MOO) search engine based on NSGA-II (Deb et al., 2002). Pareto optimal solutions of sizing and allocation of the different renewable DG technologies are found to simultaneously minimize the expected global cost $\left(E C_{g}\right)$ and expected energy not supplied (EENS).

\section{DISTRIBUTED GENERATION NETWORK}

The DG network is considered to be composed by four main classes of components: nodes, feeders, main supply spots (MS) and renewables DG units. The nodes are fixed spatial locations at which loads, main supply spots and DG units can be allocated. Feeders connect the different nodes and through them the power is distributed. MS and DG units are power sources; if electric vehicles or storage devices are considered as DG technologies, they can also act as loads when they are in charging state. The locations of the MS spots are considered fixed. An example of configuration of a DG network is show in Figure 1. 


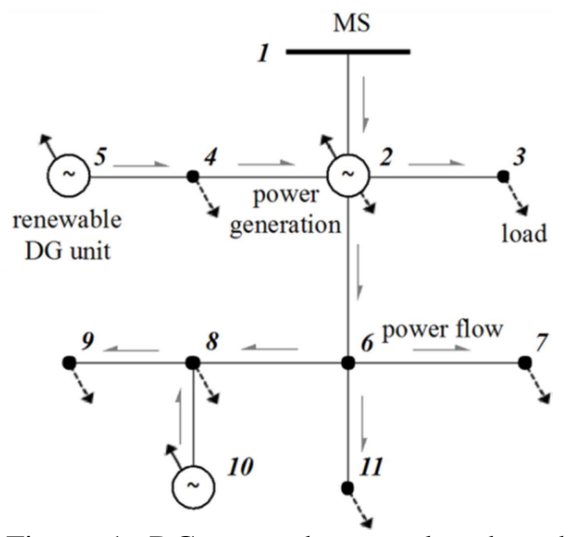

Figure 1. DG network example adapted from the IEEE 13 nodes test feeder (neglected regulator, capacitor and switch) (IEEE Power and Energy Society).

The renewable DG technologies considered are of four types: solar photovoltaic (PV), wind turbines $(\mathrm{W})$, electric vehicles (EV) and storage devices. The sets and subsets of components of the DG network are represented by the following notation:

- $N$ : set of nodes

- $n=|N|:$ number of nodes in the network

- $F D$ : set of feeders

- $M S$ : set of main supply spots

- $m=|M S|$ : number of main supply spots

- $D G$ : set of all DG technologies

- $d=|D G|:$ number of DG technologies

- $P V$ : set of all photovoltaic technologies

- $E W$ : set of all wind technologies

- $E V$ : set of all electric vehicles technologies

- $S T$ : set of all storage technologies

The location, type and size or capacity of the power sources (MS and DG) are defined in matrix form as:

$$
\Xi=\underbrace{\left[\begin{array}{ccccc:ccccc}
\xi_{1,1} & \cdots & \xi_{1, j} & \cdots & \xi_{1, m} & \xi_{1, m+1} & \cdots & \xi_{1, m+j} & \cdots & \xi_{1, m+d} \\
\vdots & \ddots & \vdots & & \vdots & \vdots & \ddots & \vdots & & \vdots \\
\xi_{i, l} & \cdots & \xi_{i, j} & \cdots & \xi_{i, m} & \xi_{i, m+1} & \cdots & \xi_{i, m+j} & \cdots & \xi_{i, m+d} \\
\vdots & & \vdots & \ddots & \vdots & \vdots & & \vdots & \ddots & \vdots \\
\xi_{n, 1} & \cdots & \xi_{n, j} & \cdots & \xi_{n, m} & \xi_{n, m+1} & \cdots & \xi_{n, m+j} & \cdots & \xi_{n, m+d}
\end{array}\right]}
$$

where, $\Xi^{M S}$ and $\Xi^{D G}$ are the main supply and DG units part of the matrix $\Xi$ respectively and $\xi_{i, j}$ is given by:

$$
\xi_{i, j}=\left\{\begin{array}{c}
\zeta \text { units } M S \text { or DG type jare allocated at node } i \\
0 \quad \text { otherwise }
\end{array}\right.
$$

Feeders deployment is defined by the set of connected nodes:

$$
F D=\left\{(1,2), \ldots,\left(i, i^{\prime}\right)\right\} \quad \forall\left(i, i^{\prime}\right) \in N \times N,\left(i, i^{\prime}\right) \text { is a feeder }
$$

In this manner, a configuration of the DG network is given by the pair $\{\Xi, F D\}$ and both power sources and feeders are subject to uncertainties, so the performance of the network is strongly dependent on the configuration and the operating scenarios.

\subsection{Modeling of uncertainties}

\subsubsection{Mechanical states of the components}

In the present paper, the components of the network i.e. MS spots, renewable DG units and feeders are considered to be affected by interruptions in their functionality due to the occurrence of failures. The components can be in the mutually exclusive mechanical states $m c$ (binary): (1) available to operate and (0) under repair. The stochastic behavior failures and repair actions is modeled by a Markov model and the duration of each state is assumed as exponentially distributed (Li \& Zio, 2012).

\subsubsection{Photovoltaic generation}

PV technology generates electrical power by transforming solar irradiance into direct current through a set of solar cells configured as panels. Usually, solar irradiance has been modeled using probabilistic distributions, derived from the weather historical data of a particular geographical area. In this paper, the Beta distribution function is used ( $\mathrm{Li}$ $\&$ Zio, 2012).

$$
f_{p v}(s)=\left\{\begin{array}{cc}
\frac{\Gamma(\alpha+\beta)}{\Gamma(\alpha) \Gamma(\beta)} s^{(\alpha-l)}(1-s)^{(\beta-1)} & \forall s \in[0,1], \alpha, \beta \geq 0 \\
0 & \text { otherwise }
\end{array}\right.
$$

where, $s$ is the solar irradiance, $f_{p v}$ the Beta probability density function and $\alpha$ and $\beta$ its parameters.

PV power generation depends on the features of the photovoltaic material and the ambient temperature on site. The power output from $n_{\text {cells }}$ solar cells is given by (Li \& Zio, 2012):

$$
\begin{aligned}
& T_{c}=T_{a}+s\left(\frac{N_{o T}-20}{0.8}\right) \\
& I=s\left(I_{s c}+k_{i}\left(T_{c}-25\right)\right) \\
& V=V_{o c}+k_{v} T_{c} \\
& F F=\frac{V_{M P P} I_{M P P}}{V_{o c} I_{s c}} \\
& P^{p v}(s)=n_{c e l l s} \times F F \times V \times I
\end{aligned}
$$

where, $T_{a}, N_{o T}, T_{c}\left[{ }^{\circ} \mathrm{C}\right]$ are the ambient, nominal cell operating and cell temperatures, respectively; $I_{s c}$ short circuit current $[A], k_{i}\left[\mathrm{~mA} /{ }^{\circ} \mathrm{C}\right]$ current temperature coefficient, $V_{o c}$ open circuit voltage $[V], k_{v}$ $\left[\mathrm{mV} /{ }^{\circ} \mathrm{C}\right]$ voltage temperature coefficient, $V_{M P P}[\mathrm{~V}]$ and $I_{M P P}[\mathrm{~A}]$ voltage and current at maximum power, respectively; $F F$ fill factor and $P^{p v} \mathrm{PV}$ power output $[W]$.

\subsubsection{Wind generation}

Wind generation is obtained from turbinealternator devices that convert the kinetic energy of the wind into mechanical-electrical power. The uncertain behavior of the wind speed is commonly represented through probability distributions, specifically the Rayleigh distribution has been widely used: 
$f_{w}(w s)=\frac{2 w s}{\sigma} e^{-\left(\frac{w s}{\sigma}\right)^{2}}$

where, $w s$ is the wind speed $[\mathrm{m} / \mathrm{s}], f_{w}$ the Rayleigh probability density function and $\sigma$ its scale parameter.

Thus, for a given value of wind speed, the output of a single wind turbine is modeled as (Atwa et al., 2010, Li \& Zio, 2012):

$P^{w}(w s)=\left\{\begin{array}{cc}P_{R T D}^{w} \frac{\left(w s-w s_{c i}\right)}{\left(w s_{a}-w s_{c i}\right)} & w s_{c i} \leq w s<w s_{a} \\ P_{R T D}^{w} & w s_{a} \leq w s<w s_{c o} \\ 0 & \text { otherwise }\end{array}\right.$

where, $w s_{c i}, w s_{a}$ and $w s_{c o}[\mathrm{~m} / \mathrm{s}]$ are the cut-in, rated and cut-out wind speeds respectively, $P_{R T D}^{w}[k W]$ the rated power and $P^{w}$ the wind power output $[k W]$.

\subsubsection{Electric vehicles}

In the present work, EV are treated as a 'block group' of battery electric vehicles with three possible operating states: charging, discharging and disconnected (Clement-Nyns et al., 2011). For a 'block group' of EV, the single operating behavior of each electric vehicle is aggregated to an overall performance. In charging state, EV behave as loads while in discharging as power sources. The dis/connection pattern is considered uncertain and represented approximating the hourly probability distribution of the operating states per day. The approximation is inferred from the percentage of trips that the vehicles perform by hour of the day with the duration intervals assigned to each operating state (ClementNyns et al., 2011).

Given a specific hour of the day $t_{d}$, the operating state of a block of EV is sampled randomly from the corresponding probabilities. Thus, the power output for a block of EV is estimated according to equations (12) and (13).

$$
\begin{aligned}
& f_{e v}\left(t_{d}, o p\right)= \begin{cases}p_{d c h}\left(t_{d}\right) & \text { op }=\text { discharging } \\
p_{c h}\left(t_{d}\right) & \text { op }=\text { charging } \\
p_{d t d}\left(t_{d}\right) & \text { op }=\text { disconnected }\end{cases} \\
& P^{e v}(o p)=\left\{\begin{array}{cc}
P_{R T D}^{e v} & o p=\text { discharging } \\
0 & \text { op }=\text { disconnect ed } \\
-P_{R T D}^{e v v} & \text { op }=\text { charging }
\end{array} \quad \forall t \in\left[0, t_{R o p}\right]\right.
\end{aligned}
$$

where, $t_{R o p}[h]$ is the residence duration for operating state $o p, f_{e v}$ the operating state probability density function and $P_{R T D}^{e v}[k W]$ the EV rated power.

\subsubsection{Storage devices}

ST technology are considered as batteries. Commonly, ST devices present two possible operating states, charging and discharging. In this study, the level of charge in the batteries is randomized and the discharging state is the only one that takes place. This allows us to treat the battery operation as nonsequential i.e. each operating state is independent from the previous one. Then, the power output per unit of mass of one storage device is calculated as follows:

$f_{s t}\left(Q^{s t}\right)=\left\{\begin{array}{cc}\frac{1}{S E \times M_{T}} & 0<Q^{s t} \leq S E \times M_{T} \\ O & \text { otherwise }\end{array}\right.$

$t_{R}^{\prime}\left(Q^{s t}\right)=\frac{Q^{s t}}{P_{R T D}^{s t}}$

$P^{s t}\left(t_{R}\right)=P_{R T D}^{s t} \quad \forall t_{R} \in\left[0, t_{R}^{\prime}\right]$

where, $Q^{s t}[k J]$ is the level of charge in the battery, $S E[\mathrm{~kJ} / \mathrm{kg}]$ the specific energy of the active chemical, $M_{T}[\mathrm{~kg}]$ the total mass of active chemical in the battery, $f_{s t}$ uniform probability density function, $P_{R T D}^{s t}$ $[k W]$ rated power and $t_{R}^{\prime}[h]$ the discharging time interval.

\subsubsection{Main power supply}

The MS spots in the DG network represent the locations of the transformers that provide the voltage level of the customers. The variability in the power supplied from the transformers is assumed following normal distribution functions limited by 0 and the maximum capacity of the transformers.

$f_{m s}\left(P^{m s}\right)=\left\{\begin{array}{cc}\frac{\frac{1}{\sigma^{m s}}\left(\frac{P^{m s}-\mu^{m s}}{\sigma^{m s}}\right)}{\Phi\left(\frac{P_{c a p}^{m s}-\mu^{m s}}{\sigma^{m s}}\right)-\Phi\left(\frac{-\mu^{m s}}{\sigma^{m s}}\right)} & 0 \leq P^{m s} \leq P_{\text {cap }}^{m s} \\ \text { otherwise }\end{array}\right.$

where, $P^{m s}[k W]$ is the available main power supply, $\mu^{m s}$ the Normal distribution mean, $\sigma^{m s}$ the Normal distribution standard deviation, $f_{m s}$ the Nomal probability density function, $P_{c a p}^{m s}[k W]$ the maximum capacity of the transformer, $\phi(\cdot)$ the standard Normal probability density function and $\Phi(\cdot)$ the cumulative distribution function of $\phi(\cdot)$.

\subsubsection{Demand of power}

The total demand of power in the network can be represented as daily load profiles deducted from historical data (Atwa et al., 2010, Ren et al., 2010). The nodal power demands are defined adopting the same behavior of the total demand profile and modeling the hourly level of load as normally distributed as shown in Figure 2.

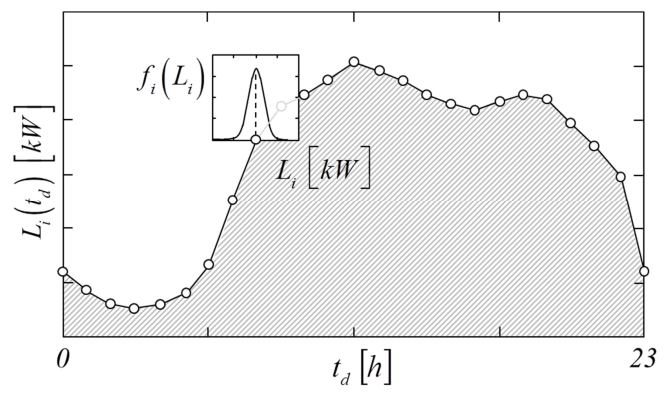

Figure 2. Daily load profile. Hourly normally distributed load. 
In this manner, the nodal power demands are modeled as:

$$
f_{L_{i}}\left(L_{i}, t_{d}\right)=\left\{\begin{array}{cc}
\frac{\frac{1}{\sigma_{i}\left(t_{d}\right)}\left(\frac{L_{i}-\mu_{i}\left(t_{d}\right)}{\sigma_{i}\left(t_{d}\right)}\right)}{1-\Phi\left(\frac{-\mu_{i}\left(t_{d}\right)}{\sigma_{i}\left(t_{d}\right)}\right)} & \text { otherwise } \\
0 & \forall i \in N, 0 \leq L_{i} \leq \infty
\end{array}\right.
$$

where, $L_{i}[k W]$ is the power demand at node $i$ and $\mu_{i}$, $\sigma_{i}$ and $f_{m s}$ the Nomal probability mean, standard deviation and density function respectively.

\section{MONTE CARLO - OPTIMAL POWER FLOW SIMULATION}

For a given DG-integrated network solution $\{\Xi, F D\}$, each uncertain variable is randomly sampled, constituting a vector $\vec{\vartheta}$ which defines an operational scenario. Then, the performance of the network is evaluated through the OPF.

$$
\begin{aligned}
\vec{\vartheta}= & {\left[t_{d}, P_{i, j}^{m s}, L_{i}, s_{i}, w s_{i}, t_{R o p_{i, j}}, Q^{\left.s t_{i, j}, m c_{i, j}, m c_{i, i^{\prime}}\right]}\right.} \\
& \forall i, i^{\prime} \in N, j \in M S \cup D G,\left(i, i^{\prime}\right) \in F D
\end{aligned}
$$

The hour of the day $t_{d}[\mathrm{~h}]$ is sampled from a uniform distribution $U(1,24)$. The night interval is defined between the 22.00 and 06.00 hours. If the value of $t_{d}$ falls in the night interval, there is no solar irradiation $(s=0)$.

\subsection{Optimal power flow formulation}

Power flow analysis is performed using a DC model which linearizes the classical non-linear conditions (Purchala \& Meeus, 2005). The assumptions of the DC power flow are:

- The difference between voltage angles are small, i.e., $\sin (\Delta \delta) \approx \Delta \delta$ and $\cos (\Delta \delta) \approx 1$.

- The feeders resistance is neglected, i.e., power losses in the feeders are neglected.

- The voltage profile is flat (constant $V$, set to 1 p.u.).

For a given DG network $\{\Xi, F D\}$ and operational scenario $\vec{\vartheta}$, the formulation of the OPF problem is:

$\min C_{O \& \notin M}^{n e t \vec{\vartheta}}\left(P_{G u}^{\vec{\vartheta}}\right)=\sum_{i \in N} \sum_{j \in M S \cup D G} C_{O \& M_{j}^{v}} \times P_{G u_{i, j}}^{\vec{\vartheta}} \times t^{S}$

s.t.

$$
\begin{aligned}
& \left(\sum_{j \in M S \cup D G} P_{G u_{i j}}^{\bar{\vartheta}}+L S_{i}^{\bar{\vartheta}}+\sum_{i \in N} m c_{i, i^{\prime}}^{\vec{\vartheta}} B_{i, i^{\prime}}\left(\delta_{i}^{\bar{\vartheta}}-\delta_{i^{\prime}}^{\bar{\vartheta}}\right)\right)-L_{i}^{\bar{\vartheta}}=0 \\
& \forall i, i^{\prime} \in N,\left(i, i^{\prime}\right) \in F D \\
& 0 \leq P_{G u_{i, j}}^{\bar{y}} \leq P_{G a_{i, j}}^{\bar{b}} \quad \forall i \in N, j \in M S \cup D G \\
& \left|m c_{i, i^{\prime}}^{\vec{\vartheta}} B_{i, i^{\prime}}\left(\delta_{i}^{\bar{\vartheta}}-\delta_{i^{\prime}}^{\bar{\vartheta}}\right)\right| \leq V \times A m p_{i, i^{\prime}} \quad \forall i, i^{\prime} \in N,\left(i, i^{\prime}\right) \in F D
\end{aligned}
$$

where, $t^{S}[h]$ is the duration of the scenario $\vec{\vartheta}, C_{O \& M}^{n e t} \vec{\vartheta}$ $[\$]$ the operating and maintenance cost $(\mathrm{O} \& \mathrm{M})$ of the total power supply MS and DG, $C_{O \& M_{j}^{v}}[\$ / k W h]$ the variable O\&M costs of the power source $j, B_{i, i}$, $[1 / \Omega]$ the susceptance of the feeder $\left(i, i^{\prime}\right), P_{G a_{i, j}}^{\vec{\vartheta}}[k W]$ the available power in the source type $j$ at node $i$, $P_{G u_{i, j}}^{\bar{\vartheta}}[k W]$ the power produced by source type $j$ at node $i, L S_{i}^{\vec{\vartheta}}[k W]$ the load shedding at node $i, V[k V]$ the nominal voltage of the network and $A m p_{i, i}$, the ampacity of the feeder $\left(i, i^{\prime}\right)$.

Load shedding is performed to alleviate overloads in the feeders and/or balance the demand of power with the available power supply.

The aim of the OPF is the minimization of the O\&M costs associated to the DG network generation and supply in the scenario $\vec{\vartheta}$. Constraints (21), (22) and (23) represent the power balance at node $i$ and the capacity and technical limits of power sources and feeders, respectively.

\subsection{Performance indicators: ENS and $C_{g}$}

The DG network solutions are evaluated with respect to the energy not supplied and global cost.

The ENS is a common index to evaluate the reliability of the supply in power systems (Billinton, 1998), and in the present work, its value corresponds to the aggregation of all-nodal load sheddings which is a direct output of the OPF for a scenario $\vec{\vartheta}_{\ell}$.

$E N S^{\vec{v}_{\ell}}=\sum_{i \in N} L S_{i} \vec{v}_{\ell} \times t^{s} \quad \forall \vec{\vartheta}_{\ell} \in Y$

With respect to $\mathrm{C}_{\mathrm{g}}$, this is composed by two terms. The first one includes the fixed investment and operation and maintenance costs which are prorated hourly over the life of the project. The second term corresponds to the variable costs that depend on the power supply and generation (OPF), and revenues associated to DG units and incentives. The distribution network is considered as a 'price taker' entity, assuming a correlation between the total load and the energy price. Then, the energy price is calculated from the following correlation (Falaghi et al., 2011, Ren et al., 2010):

$$
e p=e p_{h}\left[-0.38\left(\frac{L_{T}\left(t_{d}\right)}{L_{T h}}\right)^{2}+1.38 \frac{L_{T}\left(t_{d}\right)}{L_{T h}}\right]
$$

where, $e p$ and $e p_{h}[\$ / k W h]$ are the energy price and the energy price at maximum total load $\left(L_{T h}\right)$ respectively.

The global cost function for a scenario $\vec{\vartheta}_{\ell}$ is given by:

$$
\begin{aligned}
& C_{g}^{f}=\frac{\sum_{i \in N} \sum_{j \in D G} \xi_{i, j}\left(C_{i n v_{j}}+C_{O \& M_{j}^{f}}\right)}{t^{h}} \times t^{s} \\
& C_{g}^{v}\left(\vec{\vartheta}_{\ell}\right)=C_{O \& M}^{n e t \vec{\vartheta}_{\ell}}-\left(i n c+e p\left(L_{T}^{\vec{v}_{\ell}}\right)\right) \times \sum_{i \in N} \sum_{j \in D G} P_{G u_{i, j}}^{\vec{\vartheta}_{\ell}} \times t^{S} \quad \forall \vec{\vartheta}_{\ell} \in Y
\end{aligned}
$$


$C_{g}\left(\vec{\vartheta}_{\ell}\right)=C_{g}^{f}+C_{g}^{v}\left(\vec{\vartheta}_{\ell}\right) \forall \vec{\vartheta}_{\ell} \in Y$

where, $C_{i n v_{j}}[\$]$ is the investment cost of the DG technology $j, C_{O \& M_{j}^{f}}[\$]$ the fixed O\&M cost of DG technology $j, t^{h}[h]$ the horizon of analysis, inc $[\$ / k W h]$ the incentive for generation from renewable sources.

Figure 3 shows a flow chart of the complete MCS-OPF model.

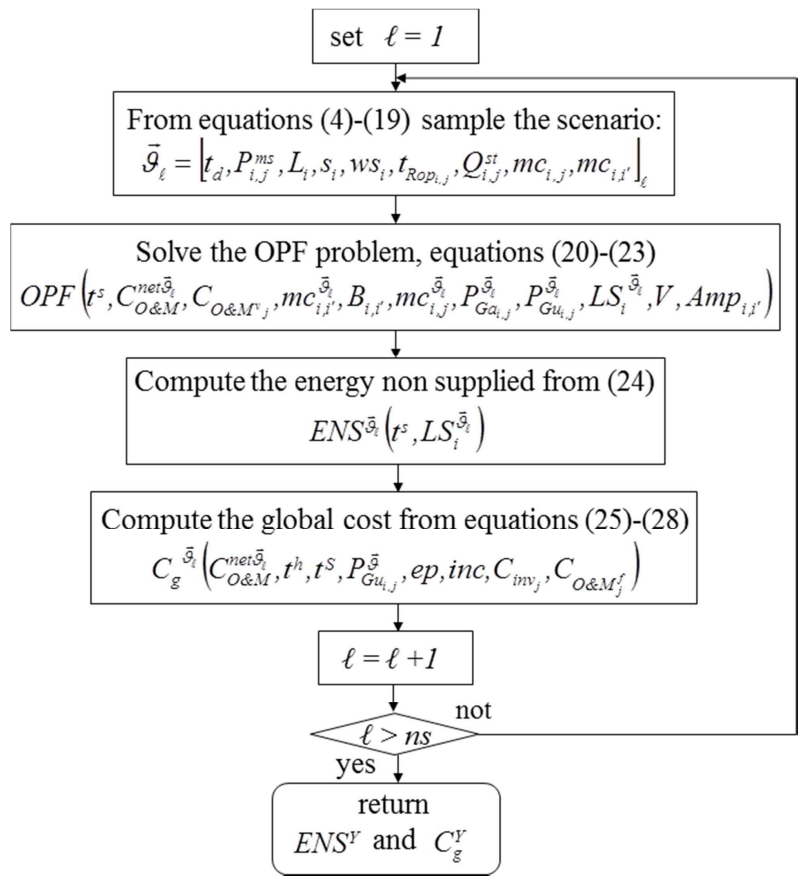

Figure 3. MCS-OPF flow chart.

\section{DG UNITS SELECTION, SIZING AND ALLOCATION}

The solution of the MOO problem is aimed of finding the optimal selection, sizing and allocation of the different renewable DG technologies available, PV, W, EV and ST.

Optimization is judged by the expected values of $E N S$ and $C_{g}$, denoted $E E N S$ and $E C_{g}$ respectively.

The MOO problem formulation, considering a set of randomly generated scenarios $Y$, is as follows:

$$
\begin{aligned}
& \min f_{1}=E C_{g}^{Y} \\
& \min f_{2}=E E N S^{Y}
\end{aligned}
$$

s.t.

Equation (2)

$\sum_{i \in N} \sum_{j \in D G} \xi_{i, j}\left(\operatorname{Cinv}_{j}+C_{O \& M_{j}^{f}}\right) \leq B G T$ $\sum_{i \in N} \xi_{i, j} \leq \tau_{j} \quad \forall j \in D G$

$O P F(\{\Xi, F D\}, Y)$

The meaning of each constraint is:

- Equation (2): the decision variable $\xi_{i, j}$ is a positive integer number.

- (31) the total investment and fixed operation and maintenance costs must be less or equal to the available budget $B G T$.

- (32) the total number of DG units to allocate of each technology $j$ must be less or equal to the maximum number of units available $\tau_{j}$ fo integration.

- (20)-(23) all equations of OPF must be satisfied.

In this paper, the MOO problem is solved by the NSGA-II algorithm, in which for each DG network solution proposed the evaluation of the two objective functions is performed by the MCS-OPF. The details of NSGA-II are described in (Deb et al., 2002).

\section{APPLICATION}

We consider a distribution network adapted from IEEE 13 nodes test feeder (IEEE Power and Energy Society). Regulator, capacitor, switch and feeders with zero length have been neglected. Since the original distribution network is dimensioned such that the total power demand is satisfied without lines overloading, we modify it so that it becomes of interest to consider the integration of renewable DG units. Some locations and values of loads and ampacity values of the feeders have been modified to generate conditions of power congestion.

\subsection{Distribution network description}

The distribution network presents a radial structure of $n=11$ nodes and $f d=10$ feeders, as shown in Figure 4. The nominal voltage is $V=4.16[\mathrm{kV}]$.

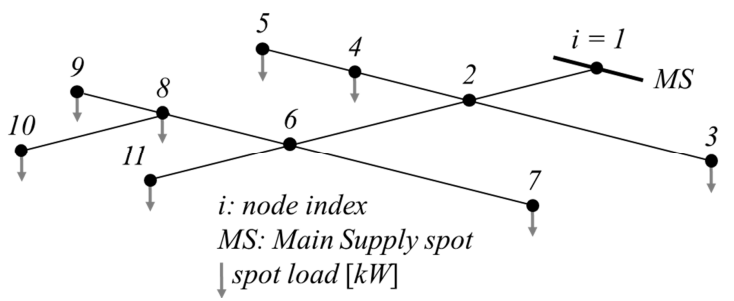

Figure 4. Radial 11-nodes distribution network.

Table 1 contains the technical characteristics of the different types of feeders considered: specifically, the indexes of the pairs of nodes that are connected by each feeder of the network, their length, reactance $X$ and their ampacity Amp. 
Table 1. Feeders characteristic and technical data (IEEE Power and Energy Society)

\begin{tabular}{llllll}
\hline Type & Node $i$ & Node $i$ & Length $[\mathrm{km}]$ & $X[\Omega / \mathrm{km}]$ & Amp $[\mathrm{A}]$ \\
\hline T1 & 1 & 2 & 0.610 & 0.371 & 365 \\
$T 2$ & 2 & 3 & 0.152 & 0.472 & 170 \\
$T 3$ & 2 & 4 & 0.152 & 0.555 & 115 \\
$T 1$ & 2 & 6 & 0.610 & 0.371 & 365 \\
$T 3$ & 4 & 5 & 0.091 & 0.555 & 115 \\
$T 6$ & 6 & 7 & 0.152 & 0.252 & 165 \\
$T 4$ & 6 & 8 & 0.091 & 0.555 & 115 \\
$T 1$ & 6 & 11 & 0.305 & 0.371 & 365 \\
$T 5$ & 8 & 9 & 0.091 & 0.555 & 115 \\
$T 7$ & 8 & 10 & 0.244 & 0.318 & 115 \\
\hline
\end{tabular}

The parameters of normally distributed power supply from the MS spot are given in Table 2.

Table 2. Main power supply parameters

\begin{tabular}{l|l|l|l}
\hline Node & $P_{\text {cap }}^{m s}[k W]$ & $\mu^{m s}$ & $\sigma^{m s}$ \\
\hline 1 & 1600 & 1200 & 27.5 \\
\hline
\end{tabular}

For this case study, the distribution region is such that the solar irradiation and wind speed values are assumed constant in the whole network.

The technical parameters of the four different types of DG technologies available to be integrated into the distribution network (PV, W, EV and ST) are given in Table 3 and the hourly per day operating states probability profile of the EV is presented in Figure 5.

Table 3. Parameters of PV, W, EV and ST technologies (Falaghi et al., 2011, Li \& Zio, 2012, Raoofat, 2011)

\begin{tabular}{llll}
\hline$P V$ & \multicolumn{3}{l}{$W$} \\
\hline Beta distr. $\alpha$ & 0.26 & Rayleigh dist. $\sigma$ & 7.96 \\
Beta distr. $\beta$ & 0.73 & $P_{R T D}^{w}[\mathrm{~kW}]$ & 50.00 \\
$W_{\text {peak }}[\mathrm{kW}]$ & 0.05 & $\mathrm{ws}_{c i}[\mathrm{~m} / \mathrm{s}]$ & 3.80 \\
$T_{a}\left[{ }^{\circ} \mathrm{C}\right]$ & 30.00 & $\mathrm{ws}_{a}[\mathrm{~m} / \mathrm{s}]$ & 9.50 \\
$N_{o T}\left[{ }^{\circ} \mathrm{C}\right]$ & 43.00 & $w s_{c o}[\mathrm{~m} / \mathrm{s}]$ & 23.80 \\
$I_{s c}[\mathrm{~A}]$ & 1.80 & & \\
$k_{i}\left[\mathrm{~mA} /{ }^{\circ} \mathrm{C}\right]$ & 1.40 & $E V$ & \\
$V_{o c}[\mathrm{~V}]$ & 55.50 & $P_{R T D}^{e v}[\mathrm{~kW}]$ & 6.30 \\
$k_{v}\left[\mathrm{mV} /{ }^{\circ} \mathrm{C}\right]$ & 194.00 & $S T$ & \\
$V_{M P P}[\mathrm{~V}]$ & 38.00 & $P_{R T D}^{s t}[\mathrm{~kW} / \mathrm{kg}]$ & 0.275 \\
$I_{M P P}[\mathrm{~A}]$ & 1.32 & $S E[\mathrm{~kJ} / \mathrm{kg}]$ & 0.042 \\
\hline
\end{tabular}

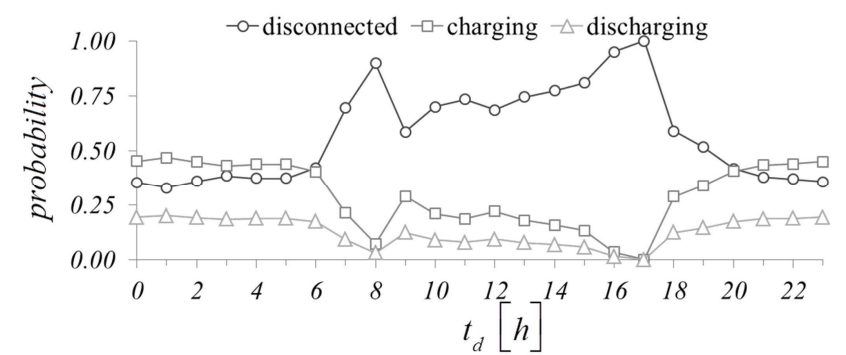

Figure 5. Hourly per day probability data of EV operating states.

The nodal power demands are reported as daily profiles, normally distributed on each hour. The mean $\mu$ and variance $\sigma$ values of the nodal daily profiles of the power demands are shown in Figure 6.

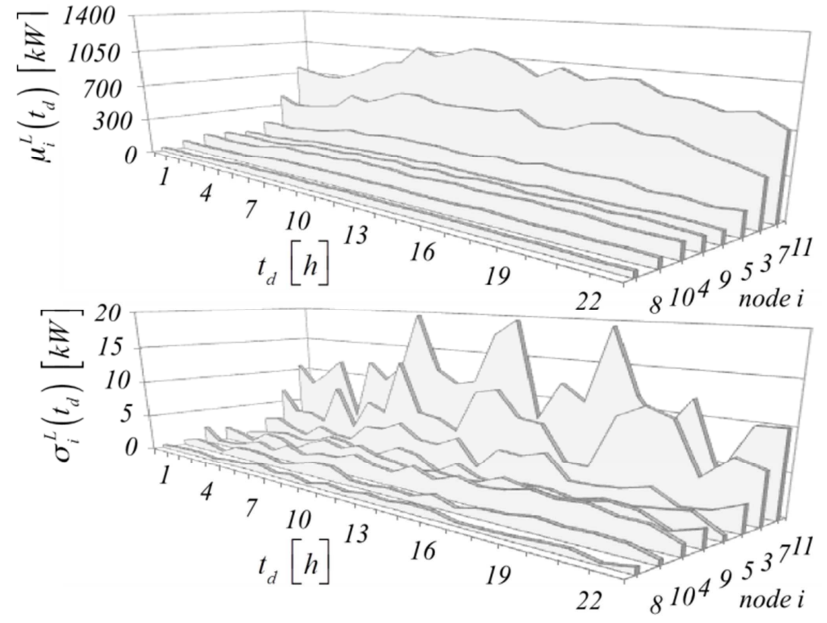

Figure 6. Mean and standard deviation values of normally distributed nodal power demand daily profiles.

Table 4 and Table 5 report the failure and repair rates of the network components and the values of the investment and fixed O\&M costs and variable O\&M respectively.

Table 4. Failure and repair rates of feeders, MS and DG units (Falaghi et al., 2011, Li \& Zio, 2012, Raoofat, 2011, Webster, 1999).

\begin{tabular}{|c|c|c|c|c|}
\hline \multirow{2}{*}{ type } & \multicolumn{2}{|c|}{$\lambda^{F}[$ failures $/ h]$} & \multicolumn{2}{|c|}{$\lambda^{R}[$ repairs $/ h]$} \\
\hline & $M S \cup D G$ & $\angle F D$ & $M S \cup D G$ & $F F$ \\
\hline$M S$ & 0.000333 & 0.000333 & 0.0206 & 0.1980 \\
\hline$P V$ & 0.000405 & 0.000405 & 0.0130 & 0.1620 \\
\hline$W$ & 0.000355 & 0.000355 & 0.0149 & 0.1850 \\
\hline$E V$ & 0.000355 & 0.000355 & 0.1050 & 0.1850 \\
\hline$S T$ & 0.000355 & 0.000355 & 0.0730 & 0.1850 \\
\hline- & - & 0.000400 & - & 0.1640 \\
\hline & - & 0.000355 & - & 0.1850 \\
\hline
\end{tabular}

Table 5. Investment, fixed O\&M and variable O\&M costs of MS and DG (Pilo et al., 2010, Webster, 1999, Zou et al., 2010).

\begin{tabular}{lll}
\hline type & $C_{i n v}+C_{O \& M^{f}}[\$ /$ unit $]$ & $C_{O \& M^{v}}[\$ / k W h]$ \\
\hline$M S$ & - & 0.1450000 \\
$P V$ & 48.00 & 0.0000376 \\
$W$ & 113750.00 & 0.0390000 \\
$E V$ & 17000.00 & 0.0220000 \\
$S T$ & 135.15 & 0.0000462 \\
\hline
\end{tabular}

Consistently with constraints (31) and (32), the limit budget is set to $B G T=4,500,000$ [\$] and the limit of units of the different DG technologies to be purchased is $\tau=[15000,5,200,8000]$. The value of the incentive is inc $=0.024$ [ $\$ / \mathrm{kWh}$ ] (Pilo et al., 2010) and the maximum value of the energy price is $e p_{h}=0.11[\$ / k W h]$ (Ren et al., 2010).

The NSGA-II run is set to perform $g=300$ generations over a population of $s z=100$ chromosomes and, the single-point crossover and mutation genetic operators are used. For the reproduction, the crossover probability is $p c o=1$, whereas the mutation probability is $p m u=0.1$; the mutation can occur simultaneously in any bit of the chromosome.

Finally, $n s=250$ random scenarios are simulated by the MCS-OPF with time step $t s=1[h]$, over an horizon of analysis of 10 years $\left(t^{h}=87600[h]\right)$, in which the investment and fixed costs are prorated hourly. 


\subsection{Results}

The Pareto front (PF) resulting from the NSGAII MCS-OPF is presented in Figure 7(A), showing non-dominated solutions (in bold) and the 'last generation' population. Each non-dominated solution corresponds to an optimal decision matrix $\Xi^{D G}$ for the sizing and allocation of the different DG technologies. Figure 7(B) shows the approximations of the histograms of $E N S$ and $C_{g}$ for three selected nondominated solutions characterized by: minimum value of $E C_{g}$, minimum value of $E E N S$ and an intermediate solution, respectively.

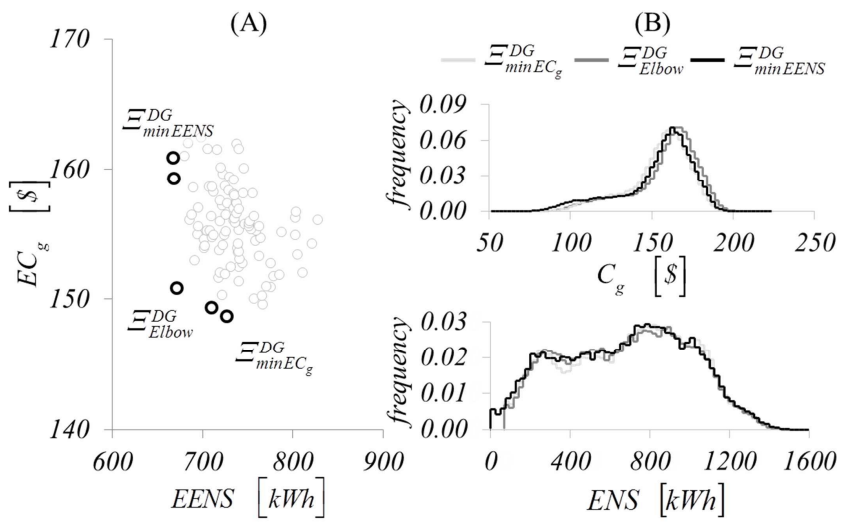

Figure 7. Pareto front (A), ENS and $C g$ histograms (B).

Table 6 presents the values of the objective functions for each of the three selected solutions and for the case without DG integration (MS).

Table 6. Expected and values of ENS and $C_{g}$.

\begin{tabular}{lll}
\hline & EENS $[\mathrm{kWh}]$ & $E C_{g}[\$]$ \\
\hline$M S$ & 1109.21 & 170.27 \\
$\Xi_{\min E C_{g}}^{D G}$ & 726.57 & 148.68 \\
$\Xi_{\text {Elbow }}^{D G}$ & 671.05 & 150.83 \\
$\Xi_{\text {min EENS }}^{D G}$ & 666.95 & 160.91 \\
\hline
\end{tabular}

Any of the optimal DG-integrated networks has a superior expected performance with respect to the MS case. This demonstrates the benefits of integrating DG, gaining reliability of power supply (lower EENS) and reducing the global cost of the network.

Table 7. $\Xi^{D G}$ configurations of selected solutions.

\begin{tabular}{|c|c|c|c|c|c|c|c|c|c|c|c|c|}
\hline \multirow{2}{*}{$\begin{array}{l}\text { Node } \\
i\end{array}$} & \multicolumn{4}{|c|}{$\Xi_{\min E C_{g}}^{D G}$} & \multicolumn{4}{|c|}{$\Xi_{\text {Elbow }}^{D G}$} & \multicolumn{4}{|c|}{$\Xi_{\min E E N S}^{D G}$} \\
\hline & $\overline{\mathrm{PV}}$ & $\mathrm{W}$ & $\mathrm{EV}$ & ST & $\overline{\mathrm{PV}}$ & $\mathrm{W}$ & EV & ST & $\overline{\mathrm{PV}}$ & $\mathrm{W}$ & EV & ST \\
\hline 1 & 62 & 0 & 0 & 0 & 62 & 0 & 0 & 14 & 21 & 0 & 6 & 1 \\
\hline 2 & 47 & & & 41 & 4 & & 0 & 41 & 4 & 0 & 0 & 0 \\
\hline 3 & 15 & & & 0 & 1 & & 0 & 16 & 1 & & 7 & 31 \\
\hline 4 & 15 & 2 & & 29 & 42 & 2 & 1 & 3 & 42 & 2 & 0 & 32 \\
\hline 5 & 14 & & & 18 & 8 & & 0 & 40 & 8 & & 0 & 40 \\
\hline 6 & 28 & 1 & & 28 & 21 & 1 & 3 & 14 & 21 & & 3 & 6 \\
\hline 7 & & & 2 & 8 & 1 & & 0 & 8 & 1 & & 0 & 9 \\
\hline 8 & 23 & 2 & & 19 & 95 & 2 & 0 & 2 & 95 & 2 & 0 & 15 \\
\hline 9 & 0 & & & 17 & 1 & & 0 & 2 & 15 & 1 & 0 & 0 \\
\hline 10 & 0 & & & & 0 & & 0 & 15 & 0 & & 0 & 10 \\
\hline 11 & 0 & & & & 25 & & 0 & 1 & 25 & & 0 & 0 \\
\hline
\end{tabular}

The configurations $\Xi^{D G}$ of the selected nondominated solutions (Table 7) indicate, in general terms, that to minimize the EENS, i.e., increase the reliability of power supply, the model tends to maintain the amount of total average DG power integrated $\left(P\left(\Xi_{\text {min }}^{D G} C_{g}\right)=461.53\right.$ and $\left.P\left(\Xi_{\text {min }}^{D E N S}\right)=474.16[k W]\right)$, installing less ST and more EV and PV power and focalizing the DG power sources at the strategic nodes 4 and 8 .

\section{CONCLUSIONS}

A computational framework for the integration of renewable generation into a distribution network has been presented. The modeling of the system has properly taken into account the main sources of uncertainty, including the inherent uncertain behavior of the primary renewable energy sources, the stochastic operating states of electric vehicles and storage, the variability of loads and the possible occurrence of failures of network components.

The proposed framework is based on NSGA-II and MCS-OPF. NSGA-II acts as search engine while MCS-OPF randomly generates realizations of the uncertain operational scenarios and evaluates the corresponding performance of the network. The optimization aims at the minimization of the expected values of energy not supplied and global cost.

A case study derived from the IEEE 13 nodes test feeder has been analyzed: the results show the capability of the framework.

\section{REFERENCES}

Alarcon-Rodriguez, A., Ault, G. \& Galloway, S. 2010. Multiobjective planning of distributed energy resources: A review of the state-of-the-art. Renewable and Sustainable Energy Reviews, 14, 1353 - 1366.

Atwa, Y. M., El-Saadany, E. F., Salama, M. M. A. \& Seethapathy, R. 2010. Optimal Renewable Resources Mix for Distribution System Energy Loss Minimization. Power Systems, IEEE Transactions on, 25, 360 -370.

Billinton, R. 1998. Reliability evaluation in modern electric power systems. Quality and Reliability Engineering International, 14, 121-122.

Borges, C. L. T. 2012. An overview of reliability models and methods for distribution systems with renewable energy distributed generation. Renewable and Sustainable Energy Reviews, 16, 4008-4015.

Clement-Nyns, K., Haesen, E. \& Driesen, J. 2011. The impact of vehicle-to-grid on the distribution grid. Electric Power Systems Research, 81, 185 - 192.

Deb, K., Pratap, A., Agarwal, S. \& Meyarivan, T. 2002. A fast and elitist multiobjective genetic algorithm: NSGA-II. Evolutionary Computation, IEEE Transactions on, 6, 182 197.

Falaghi, H., Singh, C., Haghifam, M.-R. \& Ramezani, M. 2011. DG integrated multistage distribution system 
expansion planning. International Journal of Electrical Power and Energy Systems, 33, 1489 - 1497.

Ganguly, S., Sahoo, N. C. \& Das, D. 2010. A novel multiobjective PSO for electrical distribution system planning incorporating distributed generation. Energy Systems, 1, 291-337.

Hejazi, H. A., Hejazi, M. A., Gharehpetian, G. B. \& Abedi, M. 2010. Distributed generation site and size allocation through a techno economical multi-objective Differential Evolution Algorithm. Power and Energy (PECon), 2010 IEEE International Conference on.

Ieee Power and Energy Society. Distribution Test Feeders [Online]. Available: http://ewh.ieee.org/soc/pes/dsacom/testfeeders/index.html.

Li, Y.-F. \& Zio, E. 2012. A multi-state model for the reliability assessment of a distributed generation system via universal generating function. Reliability Engineering \& System Safety, 106, 28-36.

Liu, Z., Wen, F. \& Ledwich, G. 2011. Optimal Siting and Sizing of Distributed Generators in Distribution Systems Considering Uncertainties. Power Delivery, IEEE Transactions on, 26, 2541 -2551.

Martins, V. F. \& Borges, C. L. T. 2011. Active Distribution Network Integrated Planning Incorporating Distributed Generation and Load Response Uncertainties. Power Systems, IEEE Transactions on, 26, 2164 -2172.

Pilo, F., Celli, G., Mocci, S. \& Soma, G. G. 2010. Active distribution network evolution in different regulatory environments. Power Generation, Transmission, Distribution and Energy Conversion (MedPower 2010), 7th Mediterranean Conference and Exhibition on.

Purchala, K. \& Meeus, L. 2005. Usefulness of DC power flow for active power flow analysis. Power Engineering ....

Raoofat, M. 2011. Simultaneous allocation of DGs and remote controllable switches in distribution networks considering multilevel load model. International Journal of Electrical Power and Energy Systems, 33, 1429 - 1436.

Ren, H., Zhou, W., Nakagami, K. a. T., Gao, W. \& Wu, Q. 2010. Multi-objective optimization for the operation of distributed energy systems considering economic and environmental aspects. Applied Energy, 87, 3642 - 3651.

Viral, R. \& Khatod, D. K. 2012. Optimal planning of distributed generation systems in distribution system: A review. Renewable and Sustainable Energy Reviews, 16, 5146-5165.

Webster, R. 1999. Can the electricity distribution network cope with an influx of electric vehicles? Journal of Power Sources, 217-225.

Zou, K., Agalgaonkar, A. P., Muttaqi, K. M. \& Perera, S. 2010. Multi-objective optimisation for distribution system planning with renewable energy resources. Energy Conference and Exhibition (EnergyCon), 2010 IEEE International. 